\title{
Literatura infantil portuguesa e brasileira: contributos para um diálogo multicultural
}

\author{
Eliane Debus \\ Universidade do Sul de Santa Catarina
}

Ângela BALÇA

Universidade de Évora

\begin{abstract}
RESUMO: ESTE TEXTO PRETENDE DAR VISIBILIDADE E CONTRIBUIR PARA UM DIÁLOGO ENTRE A LITERATURA INFANTIL PORTUGUESA E BRASILEIRA, CENTRANDO-SE EM TEXTOS QUE REFLETEM A QUESTÃO ÉTNICO-RACIAL, EM ESPECIAL O TEXTO PORTUGUÊS CAFÉ COM LEITE, DE ISABEL MAGALHÃES E O TEXTO BRASILEIRO CONCEIÇÃO DE VILA RICA, DE JOAQUIM BORGES.
\end{abstract}

ABSTRACT: THIS ARTICLE AIMS AT CONTRIBUTING FOR A DIALOGUE BETWEEN BRAZILIAN AND PORTUGUESE CHILDREN'S LITERATURE, FOCUSING ON TEXTS THAT REFLECT THE ETHNIC/RACIAL ISSUE, SPECIALLY THE PORTUGUESE TEXT NAMED CAFÉ COM LEITE, BY ISABEL MAGALHÃES, AND THE BRAZILIAN TEXT CONCEIÇÃO DE VILA RICA BY JOAQUIM BORGES.

PALAVRAS-CHAVE: LITERATURA INFANTIL PORTUGUESA E BRASILEIRA - MULTICULTURALISMO - ÉTNICO-RACIAL KEY-WORDS: PORTUGUESE AND BRAZILIAN CHILDREN'S LITERATURE - MULTICULTURALISM - ETHNIC/RACIAL 
ste texto, produzido a quatro mãos, apresenta o diálogo de duas pesquisadoras que, mesmo separadas pelo oceano atlântico, têm em comum a reflexão sobre a literatura de recepção infantil, em especial aquela que, em seu tecido discursivo, traz aspectos da multiculturalidade.

Vozes de dois países diferentes: Brasil e Portugal, o segundo colonizou o primeiro; foi algoz dos povos indígenas e africanos e contribuiu, política e discursivamente, para a construção do que hoje ainda temos de preconceito étnico-racial no Brasil. Lembremo-nos da Carta de Pero Vaz de Caminha, um dos primeiros exercícios de (des)construção imagética do índio. Na literatura fundacional desse português, presenciamos uma ocultação do Outro, na tentativa de "civilizá-lo". O mesmo ocorrendo com o povo africano, importado de sua terra para ser escravizado em terras brasileiras.

No que nos aproximamos e no que nos distanciamos, contemporaneamente, quando pensamos na produção dos textos literários de escritores de ambos os países, quando as personagens negras são representadas? Que espaço as narrativas tecidas pelo fio da multiculturalidade têm no mercado editorial de ambos os países? Que políticas e dizeres norteiam a existência (ou não) de uma literatura multicultural no espaço escolar? Este é o desafio deste texto e destas pesquisadoras: se não dar respostas, pelo menos iniciar um diálogo que se estenda e cumpra a função de olhar como esses dois países estão estudando a multiculturalidade na literatura de recepção infantil.

\section{Onde se contextualiza a realidade dos dois países no que diz respei- to à multiculturalidade}

Atualmente, as sociedades européias, nomeadamente a sociedade portuguesa, têm pela frente enormes desafios, em todos os níveis. Em nosso entender, um dos maiores reptos para as sociedades modernas é a questão da multiculturalidade. E, realmente, não terá sido por acaso que o ano de 2008 foi escolhido pelo Parlamento Europeu e pelo Conselho da União Européia como o Ano Europeu do Diálogo Intercultural (AEDI).

Os múltiplos eventos e diversos projetos que ocorreram ao longo daquele ano contribuíram, certamente, para conhecer um pouco melhor o Outro, para aprender a conviver com o Outro e a respeitar o Outro, num diálogo que 
possibilite a construção de redes e de teias, em que a partilha fomente uma maior aproximação mútua entre os povos.

Para Portugal, o Outro pode configurar-se como um conjunto de indivíduos, oriundos da própria Europa, que nos visitam ou que estudam, trabalham entre nós. Dentre o desconhecimento que temos de diversos países e culturas, permitimo-nos salientar os diferentes países que aderiram, mais recentemente, à União Européia, nomeadamente os denominados Países de Leste. Mas, para Portugal, o Outro se refere igualmente a todos os indivíduos oriundos dos países que compõem a CPLP - Comunidades dos Países de Língua Portuguesa.

A presença de todas essas pessoas em Portugal contribuiu em muito, certamente, para que a sociedade portuguesa tenha sofrido inúmeras transformações, resultantes de uma heterogeneidade cultural, não apenas em nível étnico, mas também em nível cultural, social, lingüístico ou mesmo religioso.

$\mathrm{Na}$ verdade, também para a sociedade portuguesa, fazem eco as palavras de Raúl Iturra (1997: 11), ao afirmar que até o começo do século XX, “[...] o mundo estava dividido em dois: 'nós' e 'eles'. 'Nós', os do povo que contempla todo o resto da humanidade; 'eles', toda a humanidade que não é 'nós'."

Com os fenômenos da emigração e da globalização, ainda para Raúl Iturra (1997: 13), "eles" e "nós" sentem a necessidade e unem-se na busca de mais vastas habilitações, através da educação, de modo a "[...] conseguir um trabalho que seja interessante para "eles" e para a sociedade multicultural que 'nós' passámos a ser." Para a sociedade portuguesa, não tem sido completamente pacífico e isento de problemas o processo de integração no seu seio de indivíduos provenientes dos mais diversos pontos de globo. Na tentativa de auxiliar a integração desses imigrantes na sociedade portuguesa, o Governo Português criou o ACIDI - Alto Comissariado para a Imigração e o Diálogo Intercultural.

Muito do trabalho a desenvolver no âmbito da multiculturalidade passa, seguramente, pela escola e pela formação de novas gerações, mais atentas, conhecedoras e respeitadoras do Outro. Em Portugal, Universidades, Centros de Investigação e outras entidades da sociedade civil procuram desenvolver investigação nesta área, contribuindo, certamente, para um melhor conhecimento do nosso tecido social e formando todos os profissionais para um desempenho cada vez mais competente em relação a essas questões.

Diferentemente, no Brasil, a diversidade multirracial está entrelaçada em sua origem: o povo indígena que aqui habitava, o negro africano escravizado 
pelo homem branco e o homem branco português. Convívio não pacífico, de submissão dos dois primeiros ao último. Nos últimos anos, várias políticas afirmativas têm merecido destaque na tentativa de superar anos de discriminação das minorias, em especial no espaço escolar: inserção da temática da Pluralidade cultural como tema transversal nos Parâmetros Curriculares Nacionais (1996); a Lei n ${ }^{\circ} 10.639 / 03$, que institui a obrigatoriedade do ensino de História e Cultura Afro-Brasileira e Africana e as Diretrizes Curriculares Nacionais para a Educação das Relações Étnico-Raciais e para o Ensino de História e Cultura Afro-Brasileira (julho/2004), bem como a Lei no 11.645/08, instituindo História e Cultura Afro-Brasileira e Indígena.

As exigências da Lei $n^{\circ}$ 10.639/03-MEC, que instituiu a obrigatoriedade do ensino de História e Cultura Afro-Brasileira e Africana no currículo escolar do ensino fundamental e médio, culminaram com o florescimento de um nicho mercadológico a partir da necessidade de livros que tematizem e problematizem as questões étnico-raciais, por meio da representação de personagens negras como protagonistas e narrativas que focalizem o continente africano como múltiplo; desfazendo idéias enraizadas como aquelas que trazem as personagens negras em papéis de submissão e/ou retratando o período escravista, bem como a representação do continente africano pelo viés do exótico.

Poderíamos, num primeiro momento, acreditar que o crescente aumento de narrativas que apresentam personagens negras seja uma estratégia política de dominação, concedida pela cultura dominante e a ela atrelada, por isso negá-la deveria ser uma prerrogativa. No entanto, esse eco das "vozes das margens", nesse caso específico na literatura para crianças, é resultado do que Stuart Hall nomeia "de políticas culturais da diferença, de lutas em torno da diferença, da Produção de novas identidades e do aparecimento de novos sujeitos no cenário político e cultural" (HALL, 2003: 320).

No caso brasileiro, a criação de leis, bem como a elaboração das Diretrizes Curriculares Nacionais para a Educação das Relações Étnico-Raciais e para o Ensino de História e Cultura Afro-Brasileira (julho/2004), veio dialogar com o Movimento Negro, que tem, nos últimos anos, acentuado a discussão sobre a inclusão da temática da discriminação e do preconceito racial, em especial no espaço escolar.

Sendo assim, não é válido entendermos esse prenúncio de acréscimo de títulos que apresentam a cultura africana e afro-brasileira somente pelo viés merca- 
dológico de aproveitamento de um nicho, seguindo a linha de Hall (2003: 320), que observa a necessidade de um afastamento das duas grandes contranarrativas, que se opõem numa eterna divisão: vitória total ou de total cooptação, quando se pensa nos discursos sobre as "etnicidades marginalizadas".

No que diz respeito à produção literária de recepção infantil brasileira, constata-se, nos últimos anos, um crescente número de autores debruçando-se sobre o tema. Na pesquisa "A representação do negro na literatura brasileira para crianças e jovens: negação ou construção de uma identidade?”, realizada junto ao Programa de Incentivo à Pesquisa da Unisul no ano de 2006, mapeamos a produção literária para crianças a partir de sete catálogos de casas editoriais (Ática, Companhia das Letrinhas, DCL, FTD, Paulinas, Salamandra e Scipione - 2005). Como resultado do estudo, pôde-se constar que a representação de personagens negras na literatura infantil, mesmo tendo ganhado, nos últimos anos, mais espaço nas editoras, ainda ocupa um lugar muito pequeno, em relação ao total de títulos. Do total de 1.785 títulos levantados, 79 trazem personagens negras, e, das editoras investigadas, as que mais têm se dedicado à temática são a DCL e a Paulinas. Os escritores Rogério Andrade Barbosa, Joel Rufino dos Santos e as escritoras Georgina Martins e Heloisa Prieto são os que têm mais títulos dedicados ao tema.

É necessário nos debruçarmos sobre essa produção e analisarmos o quanto essas narrativas, em acréscimo no mercado editorial, colaboram, ou não, para uma discussão produtiva sobre os aspectos da multiculturalidade no Brasil.

\section{Reflexões sobre a multiculturalidade}

O conceito de multiculturalidade é um conceito que nos chega do mundo anglo-saxônico (FERREIRA, 2003). Quanto a nós, entendemos este conceito de um ponto de vista holístico, no qual se incluem questões de várias ordens, não só étnica, mas também cultural, lingüística, religiosa, sexual, social. Todas essas questões se encontram presentes nas sociedades contemporâneas, globalizadas, mas nem sempre são compreendidas, ou aceitas e, em muitas delas, estamos ainda longe de uma harmoniosa coexistência.

No final dos anos de 1980, do século passado, James Banks e Cherry Banks, nos Estados Unidos da América, delinearam o conceito de literacia 
multicultural, que se configurava como uma nova literacia, como uma outra aquisição básica a fazer pelos indivíduos, nas complexas socidades atuais (SOUTA, 1997: 48). De acordo com esses investigadores, os dois elementos fundamentais para a promoção de uma literacia multicultural seriam "[...] ver o conhecimento como uma construção social e entendê-lo segundo diferentes perspectivas culturais [...]" (SOUTA, 1997: 48).

Assim, pensamos que toda a sociedade terá um papel a desempenhar na promoção dessa nova aquisição básica e, como já afirmamos noutro lugar, parece-nos que a escola, sendo um lugar privilegiado para a formação integral do indivíduo, onde se procura o crescimento e o amadurecimento de cada aluno em todas as suas dimensões, terá, também ela, um papel extraordinariamente importante a desempenhar na promoção de uma literacia multicultural, junto aos mais jovens (SEABRA; BALÇA, 2008).

Esse papel da escola poderá ser consubstanciado das mais diversas formas, tendo em conta a escola como um todo ou tendo em conta, igualmente, as diversas disciplinas e respectivos materiais didáticos.

Quer na escola quer na sociedade em geral, os textos literários para a infância são, também, o reflexo das nossas sociedades multiculturais, já que abordam, não raras vezes, questões como a identidade e a alteridade, a etnia e a cultura, a língua. Cabe, então, ao adulto mediador aproximar dos pequenos leitores essas obras e, com eles, potencializar um exercício de exegese, que lhes permitirá um entendimento pleno de valores sociais e de valores éticos que o texto literário encerra, a par de valores literários e de valores estéticos.

O texto literário, segundo Azevedo (2006: 19), como qualquer outra produção de natureza cultural, partilha com o seu leitor valores de natureza social, cultural, histórica ou ideológica, mas que lhe são dados a ler de forma não explícita, através da negociação de sentidos, celebrada no diálogo entre o leitor e o texto.

No entanto, quando nos debruçamos sobre os livros para crianças, que abordam temáticas que nos remetem para a questão da multiculturalidade, a fronteira entre o literário e o não-literário pode ser muito tênue e de difícil percepção. Por outro lado, o próprio entendimento, num sentido mais restrito, do conceito de multiculturalidade, privilegiando-se uma vertente em detrimento da outra, pode dificultar a clarificação dessas fronteiras.

A esse propósito, relembramos, por exemplo, a designação de "literatura infantil e juvenil multicultural" apresentada pelas investigadoras espanholas Isa- 
bel Pascua Febles, Gisela Marcelo Wirnitzer, Ángeles Perera Santana e Elisa Ramón Molina (2007). No capítulo assinado por Ángeles Perera Santana e Elisa Ramón Molina (2007: 87), denomina-se "literatura infantil multicultural” o conjunto de obras “[...] cuyo tema principal o cuya ambientación es la cultura de otras zonas del mundo y de otros grupos étnicos; [...]" ou, como afirmam mais à frente, "[...] sin embargo, delimitamos como literatura infantil multicultural aquellas obras cuyos protagonistas pertenecen a culturas minoritarias." (PERERA; RAMÓN, 2007: 98).

$\mathrm{Na}$ verdade, essa designação e essa interpretação da expressão "literatura infantil multicultural" parece-nos muito redutora, e mesmo, potenciadora de alguns equívocos.

As investigadoras portuguesas Carlinda Leite e M. Lurdes Rodrigues avançam, num estudo do ano 2000, quanto ao conceito de livros multiculturais, já referido por nós noutro texto (SEABRA; BALÇA, 2008). Para essas autoras (2000: 15), livros multiculturais são aqueles que valorizam e respeitam a diversidade de culturas, apresentando, alguns deles, intenções claramente pedagógicas. De acordo com esse estudo, dentro dos livros multiculturais encontram-se obras de literatura infantil.

Embora essa designação nos pareça mais abrangente, também ela não está isenta de algum reducionismo em relação aos textos literários para os mais novos, que possam revelar preocupações de caráter multicultural.

No entanto, não ignoramos que o mercado editorial coloca, à disposição dos leitores mais novos, um conjunto de textos literários que refletem a sociedade multicultural em que vivemos, e que ela pode apresentar-se de uma forma mais ou menos explícita. Nesse sentido, com este texto pretendemos dar visibilidade e contribuir para um diálogo frutífero e consistente entre a literatura infantil portuguesa e brasileira, centrando-nos em textos que refletem a questão étnica, multirracial, dando o seu contributo, certamente, para um melhor entendimento, por parte dos leitores mais novos, dessas questões, que ainda marcam as sociedades contemporâneas.

Para isso, analisaremos neste artigo o texto português é Café com leite (Calendário, 2008), de Isabel Magalhães, com ilustrações de Rita Madeira e o texto brasileiro Conceição de Vila Rica (Paulinas, 2000), de Joaquim Borges, com ilustrações de Denise Nascimento. 
No primeiro título analisado, a capa e a contracapa do álbum assinado por Isabel Magalhães e Rita Madeira parecem uma porta de entrada anunciando um texto verbal e um texto icônico pleno de estereótipos, em relação às questões raciais e culturais, transmitidos através de associações e de sensações cromáticas. O título Café com leite, que nos remete para as cores (ou eventualmente para a associação) dessas duas bebidas, o negro do café e o branco do leite, conjugado com a ilustração da capa - dois meninos, um negro de carapinha e um branco de cabelo loiro - corresponde exatamente às representações preconcebidas, relacionadas com as etnias correspondentes. O texto presente na contracapa, um excerto da narrativa, confirma de imediato essa primeira impressão e análise. $\mathrm{O}$ menino branco é conotado com a cor do leite ou das claras em castelo e o menino negro com a cor do café da senzala. A contracapa apresenta, ainda, uma ilustração dos dois meninos abraçados, o que pode remeter para - ou, eventualmente, antecipar - a mensagem da amizade, do entendimento, do respeito mútuo, entre indivíduos de etnias diferentes.

Uma breve análise do texto icônico permite-nos observar a dicotomia presente nas ilustrações, e já perfilada nos outros elementos paratextuais do livro. Desse modo, o menino branco vive numa cidade, onde predominam os prédios e os automóveis; o menino negro vive em meio rural, onde predominam as palhotas (casas de pedra com telhados de colmo); os trajes e os costumes associados aos povos africanos, como sejam, transportar as crianças às costas ou usar utensílios como o pilão; os animais como o macaco, a zebra, a girafa, o elefante e o hipopótamo.

Assim, ilustrações e texto apresentam à criança leitora uma Europa com "muita gente de raça branca" e "muitas cidades" e uma África "com muita gente de raça negra", e, pelo visto, sem muitas cidades; imagem, parece-nos, muito redutora das duas realidades. Igualmente, a caracterização do modo de vida das duas crianças é feita em contraponto, e surge-nos, mais uma vez, de modo muito simplificador - o menino branco vive numa cidade, come fast food, veste e calça de acordo com as marcas, brinca no jardim, os passatempos privilegiam as inovações eletrônicas e, como animal de estimação, tem um cão; o menino negro vive na grande planície, come comida feita pela mãe, "não precisa de roupa e, nem tão pouco, de sapatos", brinca ao ar livre e é amigo de todos os animais da floresta. 
Depois, a narrativa segue o curso, eventualmente, já projetado pelo leitor - a guerra chega ao país do menino negro - Angola - e ele foge para Portugal, onde terá de aprender a viver na grande cidade e, pior do que tudo, enfrentar situações de discriminação por parte das outras crianças. Essas situações de discriminação acontecem na escola, entre as próprias crianças. $\mathrm{O}$ texto icônico é, aqui, bastante revelador e alarga o próprio texto verbal, uma vez que nos retrata uma sala de aula, onde o menino negro está sozinho numa mesa, sem colegas, ao passo que os carrancudos meninos brancos partilham a mesa entre si.

O papel da escola, enquanto local de convívio e aceitação entre pares e enquanto lugar de formação das gerações mais novas, é, aqui, evidenciado, uma vez que "[a] única pessoa de quem ele [o menino negro] era amigo, e que o estimava, era a sua professora", cabendo, seguramente, a todos os docentes, a plena integração e aceitação de todos os alunos na turma e na escola.

O menino negro é aceito pelo Outro no dia em que, arriscando a sua própria vida, consegue salvar o menino branco, nesse caso, de morrer afogado. O texto escrito continua aqui a evidenciar a diferença do menino negro, uma vez que conseguiu pôr a salvo o menino branco porque estava "habituado a nadar lá nos rios do seu país".

De acordo com António Manuel Couto Viana (2008), o anti-racismo presente nessa história não resulta de os homens serem todos iguais, mas sim do ato heróico do menino. Concordamos, em parte, com essa leitura do texto em causa. $\mathrm{Na}$ verdade, não nos parece abusivo inferir do texto escrito e do texto icônico que os meninos brancos passaram a aceitar o menino negro, após o salvamento. No entanto, as reflexões do menino branco, que se tornou amigo inseparável, para sempre, do menino negro, é certo após ter sido salvo, evidenciam a aceitação do Outro, porque todos os homens são iguais.

Esse pequeno álbum, destinado aos leitores mais novos, encerra uma narrativa plena de estereótipos, com uma história repetitiva e comum a outras obras para esta faixa etária, que abordam a temática da aceitação da diversidade e da não discriminação. Se, por um lado, chama a atenção para a questão multirracial; por outro, está longe de oferecer aos pequenos leitores uma visão menos maniqueísta e mais real da sociedade coetânea.

O livro Conceição de Vila Rica, de Joaquim Borges tem como protagonista uma menina negra que tem, na escola, o apelido de Cafuringa, devido ao cabelo que 
"era crespo, puxado, quase espetado". A descrição do narrador das reações da menina, "bem moreninha", diante do apelido é contraditória. Num primeiro momento ela finge que o apelido é prova de carinho e é "tolerante" com as outras crianças, "não se importou muito com o novo nome". Em casa, a menina ficava "calada e tristinha", e a mãe deduziu que era por causa do apelido. A professora, então, intervém, explicando que o nome da menina é Conceição e assim deve ser tratada, tal fato acontece, porém, não pelo reconhecimento étnico da menina, mas motivado por um ato heróico da mãe.

Como na narrativa de Café com leite, de Isabel Magalhães, a menina não é aceita pelo grupo por suas qualidades específicas, mas porque sua mãe salva um menino da escola, ao doar a ele o sangue dela própria, quando este sofre um acidente: "No outro dia a menina moreninha chegou à porta da escola e quase todos os colegas vieram abraçá-la. Só depois de muito lero-lero é que ela ficou sabendo que o acidentado que sua mãe ajudou a salvar era o Junin, dos olhos azuis, da classe dos fundos”. Assim, as diferenças são equalizadas pelo ato de heroísmo.

A discriminação e a dificuldade nas relações sociais das crianças negras em nossa sociedade, em especial na escola, são tematizadas nesse livro. O papel mediador do professor nas relações de conflito, porém, aparece somente quando a turma já trata a menina "com mais respeito".

Se a atuação da professora não foi decisiva, ela colaborou para o novo relacionamento entre a turma, quando apresentou a reprodução de duas pinturas do Mestre Athayde, no teto da igreja de São Francisco de Assis e na igreja de Santa Efigência, em Ouro Preto, Minas Gerais. Ao destacar que o artista retratou uma santa mulata no centro da pintura, envolveu a turma, aguçando sua curiosidade ao tema, levando as crianças a refletirem sobre como o negro está inserido em nossa história e cultura, a importância de suas expressões e vivências. No entanto, a história de Conceição, "Çãozinha", se enreda com a dos artistas via histórico de seus ancestrais, construtores e artistas, tendo ela uma "herança artística" da qual não se vangloria.

Constata-se, assim, que as diferenças são equalizadas na narrativa pelo ato heróico da mãe e pela herança artística da menina que possui ancestrais vinculados aos grandes artistas mineiros. Outro fato que precisa ser anunciado é a descrição da menina, a qual, do início ao fim da narrativa, é apresentada como "moreninha", terminologia que se enquadra no que Souza (2005) de- 
nomina "pacto de convivência" por conferir ao imaginário social "uma posição mais sociável ao sujeito", fato que mascara a identidade negra, colaborando mais para a discriminação racial do que para a promoção da igualdade étnico-racial.

\section{Considerações, ainda que provisórias}

Muito embora as realidades brasileira e portuguesa sejam diferentes, o repto da multiculturalidade marca ambas as sociedades nos tempos contemporâneos. Os textos de literatura infantil configuram-se como um pequeno, mas decisivo, contributo para a promoção de uma literacia multicultural, junto às gerações mais novas. Em alguns desses textos, quer portugueses quer brasileiros, as personagens negras são, ainda, representadas com olhares estereotipados, estando essas narrativas longe de ocuparem um espaço equilibrado no mercado editorial. Como evidenciado nos títulos analisados, eles respondem às novas demandas da sociedade, aproveitadas ferozmente pelo mercado editorial, ao chamar a atenção para a questão multirracial.

Com este estudo procuramos dar uma primeira resposta às questões que colocamos inicialmente, num percurso que terá de ser aprofundado em investigações futuras.

\section{Referências Bibliográficas}

AZEVEDO, Fernando. Literatura infantil: recepção leitora e competência literária. In: AZEVEDO, Fernando (Org.). Lingua materna e literatura infantil. Elementos nucleares para professores do Ensino Básico. Lisboa: Lidel, 2006.

BORGES, Joaquim. Conceição de Vila Rica. São Paulo: Paulinas, 2000.

BRASIL. Ministério da Educação. Diretriz̧es Curriculares Nacionais para a Educação das Relações Étnico-Raciais e para o Ensino de História e Cultura Afro-Brasileira e Africana. Brasília/DF: MEC, 2004.

FERREIRA, Manuela. Educaşão intercultural. Lisboa: Universidade Aberta, 2003.

HALL, Stuart. Que "negro" é esse na cultura negra? In: . Da Diáspora: identidade e mediações culturais. Trad. Adelaine La Guardiã Resende et al. Belo Horizonte: Ed. UFMG, 2006. 
ITURRA, Raúl. Prefácio. In: SOUTA, Luís. Multiculturalidade e educação. Porto: Profedições, 1997.

LEITE, C.; RODRIGUES, M. Contar um conto, acrescentar um ponto. Uma abordagem intercultural na análise da literatura para a infância. Lisboa: Instituto de Inovação Educacional, 2000.

MAGALHÃES, Isabel; MADEIRA, Rita (Ilust.). Café com leite. Calendário: s/c, 2008. PERERA, Ángeles; RAMÓN, Elisa. La literatura infantil multicultural y su aplicación en el aula. In: PASCUA, Isabel et al. Literatura infantil para una educación intercultural: traducción y didáctica. Las Palmas: Universidad de Las Palmas de Gran Canaria, 2007.

SEABRA, Estrela; BALÇA, Ângela. Ecos de multiculturalidade na literatura infantil: os livros multiculturais. In: DEBUS, Elianes (Org.). A literatura infantil e juvenil de lingua portuguesa: leituras do Brasil e d'além mar. Blumenau: Nova Letra, 2008.

SOUTA, Luís. Multiculturalidade e educação. Porto: Profedições, 1997.

SOUZA, Francisca Maria do Nascimento. Linguagens escolares e reprodução do preconceito. In: Educação anti-racista: caminhos abertos pela Lei Federal no 10.639/03. Brasília: Ministério da Educação; Secretaria da Educação Continuada, Alfabetização e Diversidade, 2005.

VIANA, António Manuel Couto. <www.leitura.gulbenkian.pt/index.php?area=rol\&t ask=view\&id=30216> Acessado em 10/11/2008. 